\title{
Rol genes enhance the biosynthesis of antioxidants in Artemisia carvifolia Buch
}

\author{
Erum Dilshad', Hammad Ismail', Ihsan-ul- Haq ${ }^{2}$, Rosa Maria Cusido³, Javier Palazon², \\ Karla Ramirez-Estrada ${ }^{3}$ and Bushra Mirza ${ }^{1 *}$
}

\begin{abstract}
Background: The secondary metabolites of the Artemisia genus are well known for their important therapeutic properties. This genus is one of the valuable sources of flavonoids and other polyphenols, but due to the low contents of these important metabolites, there is a need to either enhance their concentration in the original plant or seek alternative sources for them. The aim of the current study was to detect and enhance the yield of antioxidant compounds of Artemisia carvifolia Buch. HPLC analysis was performed to detect the antioxidants. With the aim of increasing flavonoid content, Rol gene transgenics of $A$. carvifolia were established. Two genes of the flavonoid biosynthetic pathway, phenylalanine ammonia-lyase and chalcone synthase, were studied by real time qPCR. Antioxidant potential was determined by performing different antioxidant assays.

Results: HPLC analysis of wild-type A. carvifolia revealed the presence of flavonoids such as caffeic acid (30 $\mu \mathrm{g} / \mathrm{g} \mathrm{DW}$ ), quercetin $(10 \mu \mathrm{g} / \mathrm{g}$ DW), isoquercetin $(400 \mu \mathrm{g} / \mathrm{g}$ DW) and rutin $(300 \mu \mathrm{g} / \mathrm{g}$ DW). Compared to the untransformed plants, flavonoid levels increased 1.9-6-fold and 1.6-4-fold in rol B and rol C transgenics, respectively. RT qPCR analysis showed a variable expression of the flavonoid biosynthetic genes, including those encoding phenylalanine ammonia-lyase and chalcone synthase, which were found to be relatively more expressed in transformed than wild-type plants, thus correlating with the metabolite concentration. Methanolic extracts of transgenics showed higher antioxidant capacity, reducing power, and protection against free radical-induced DNA damage. Among the transgenic plants, those harboring rol $B$ were slightly more active than the rol C-transformants.

Conclusion: As well as demonstrating the effectiveness of rol genes in inducing plant secondary metabolism, this study provides insight into the molecular dynamics of the flavonoid accumulation pattern, which correlated with the expression of biosynthetic genes.
\end{abstract}

Keywords: Agrobacterium tumefaciens, Artemisia carvifolia Buch, antioxidant assays, Chalcone synthase, Flavonoids, Phenylalanine ammonia-lyase, Rol gene

\section{Background}

Artemisia is a diverse and economically important genus belonging to the family Asteraceae, with over 300 species [1]. This genus is a source of valuable secondary metabolites and essential oils used in the treatment of various diseases [2]. Phenols in general and flavonoids in particular are one of the most important groups of phytochemicals in plants, affecting oxidative stability, appearance, taste and odor. The biological properties shown by these compounds include antioxidant, anti-cancer and anti-

\footnotetext{
* Correspondence: bushramirza@qau.edu.pk

${ }^{1}$ Department of Biochemistry, Faculty of Biological Sciences, Quaid-i-Azam

University, Islamabad, Pakistan

Full list of author information is available at the end of the article
}

aging effects, as well as protection against different heart and immune diseases and brain dysfunction caused by Parkinson's, Alzheimer's and Huntington's diseases [3, 4].

Flavonoid biosynthesis starts with the amino acid Lphenylalanine [5] and leads to the formation of 4coumaroyl CoA by the phenylproponoid pathway [6]. The key enzyme of this pathway is phenylalanine ammonia-lyase $(P A L)$ [7], others being cinnamate 4hydroxylase $(C 4 H)$ and 4-coumarate: CoA ligase $(4 C L)$ [6]. Chalcone synthase $(C H S)$, which catalyzes the first committed step of the flavonoid pathway, is involved in the production of naringenin chalcone by combining one coumaroyl CoA molecule with three malonyl CoA 
molecules. Chalcone isomerase $(\mathrm{CHI})$ further isomerizes the chalcone to flavanone and from this step onward the pathway diverges to form diverse classes of flavonoids (Fig. 1).

The Artemisia genus is a particularly rich source of flavonoids [8]. While A. апnua is the most extensively studied species, resulting in the isolation of around 50 flavonoids, these antioxidants have also been detected in other species, including $A$. absinthium L [9], A. asiatica [10], A. Herba-Alb [11]. However, the flavonoid concentration is usually very low and highly variable, not only among different chemotypes but also in the same plant at different growth stages [12].

Among different strategies used to improve plant secondary metabolite production, recombinant DNA technology has allowed the expression of biosynthetic genes to be altered, and the manipulation of metabolic traits [13]. Several studies show that rol genes are powerful activators of secondary metabolism in various plants [14]. Protein of the rol A gene binds to DNA and stimulates growth, whereas the $\operatorname{rol} B$ gene is involved in the regulation of the auxin signal transduction pathway [15] and is a potent inducer of plant secondary metabolism, increasing the resveratrol production in Vitis amurensis [16] and anthraquinones in Rubia cardifolia [17]. The rol C gene encodes cytokinin glucosidase and stimulates the production of many secondary compounds in various plants [18-22].

In previous work, we obtained $\operatorname{rol} B$ and rol $C$ transformants of $A$. carvivolia Buch with a high yield of antimalarial compounds as well as higher transcript levels of biosynthetic genes than the wild-type plant [21]. The objective of the current study was to enhance the content of flavonoids in Artemisia carvifolia Buch transgenics after their detection in the wild-type plant. We carried out real time qPCR analysis of flavonoid biosynthetic genes to find a relationship between their expression levels and metabolite concentration. In this regard, two genes of the phenylpropanoid pathway of flavonoid biosynthesis were studied: those encoding $P A L$ and CHS. The flavonoids were quantified by HPLC, and antioxidant activity was measured by performing different antioxidant assays.

\section{Results and discussion}

HPLC-DAD-based quantification of flavonoids

Qualitative and quantitative analysis of flavonoids in shoots of wild-type and transformed A. carvifolia plants (4-month-old) was carried out using an HPLC-DAD system. Eight flavonoid markers (caffeic acid, quercetin, isoquercetin, rutin, catechin, apigenin, gallic acid and kaempferol) were studied, out of which four (caffeic acid, quercetin, isoquercetin and rutin) were detected in the wild-type plant and with an enhanced concentration in the rol gene transformants. Catechin and apigenin were detected in the transformed but not the wild-type plants (Fig. 2).

While the concentration of caffeic acid was $30 \mu \mathrm{g} / \mathrm{g}$ DW in the wild-type plant, in the $\operatorname{rol} B$ transformants it

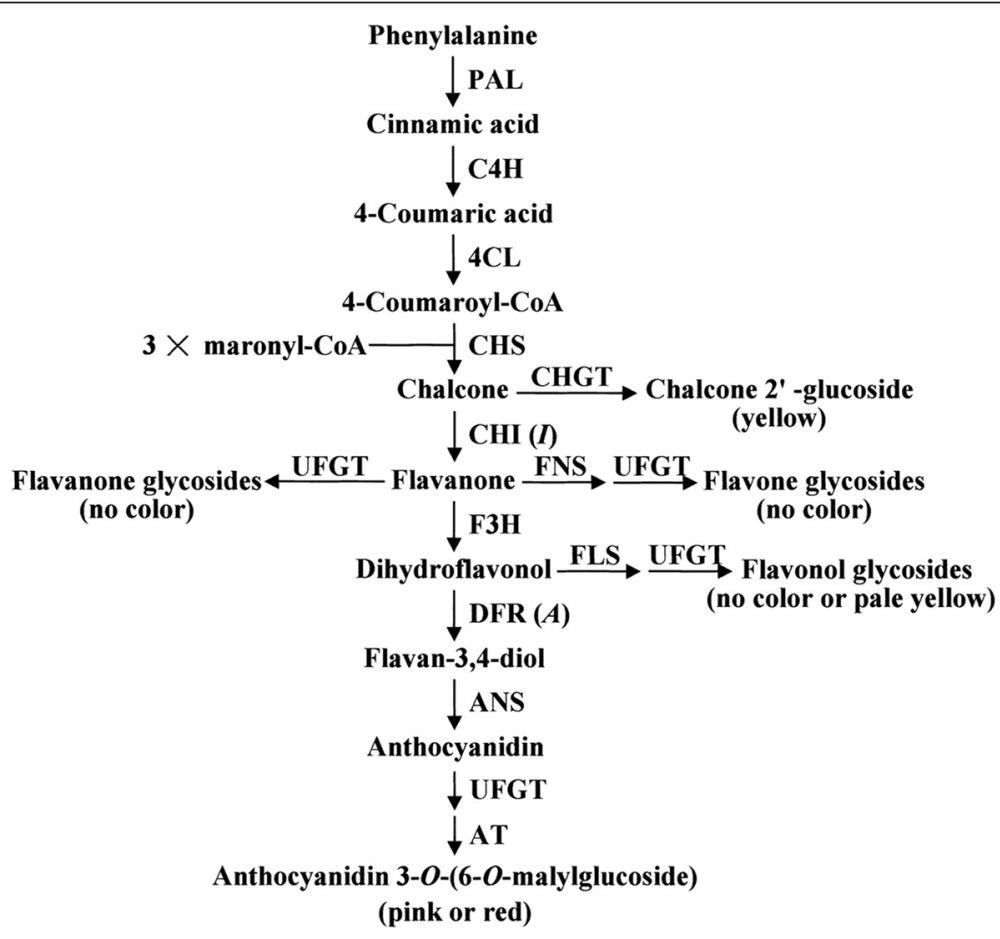

Fig. 1 Flavonoids biosynthetic pathway [57] 


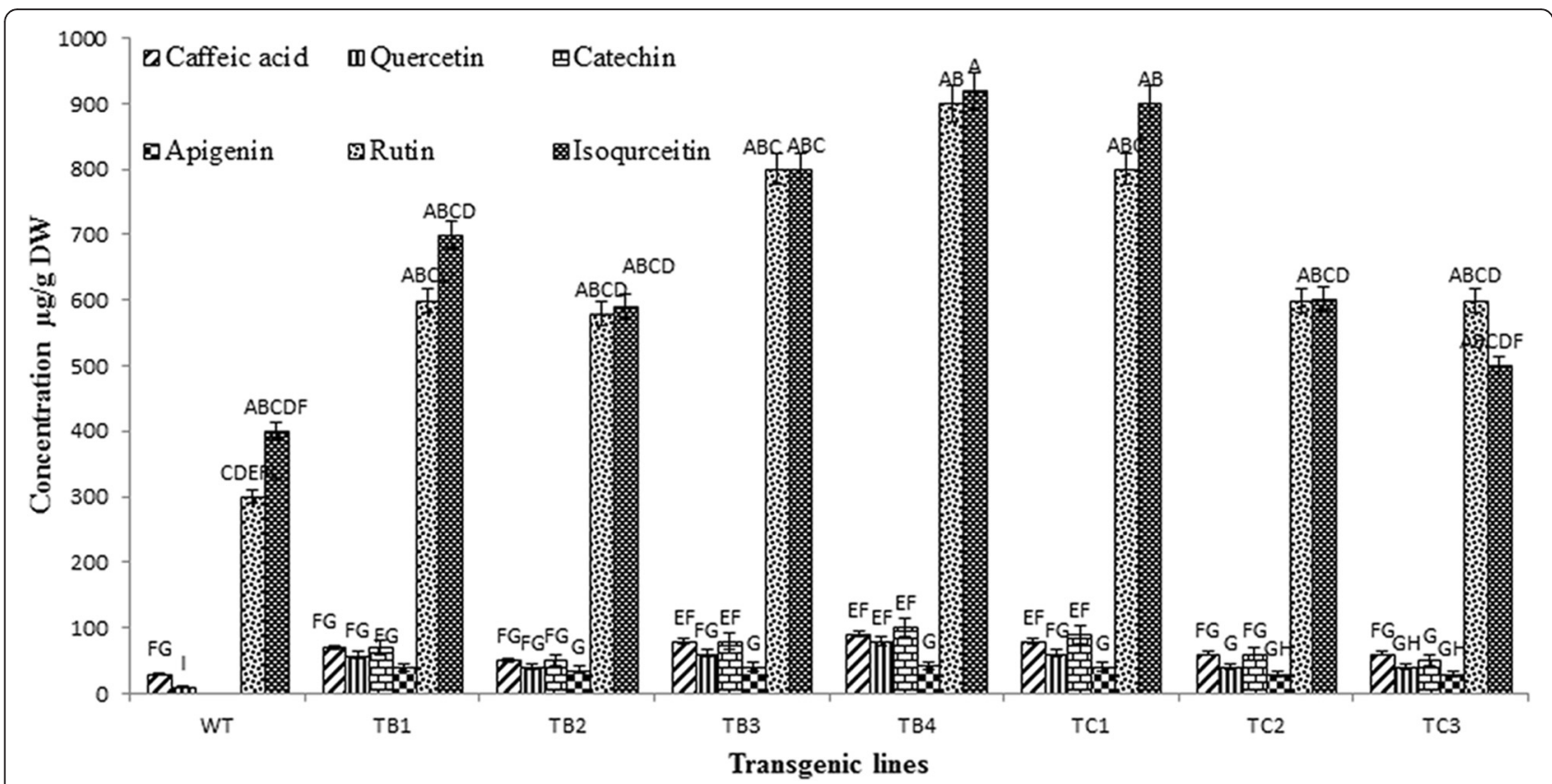

Fig. 2 Comparative and statistical analysis of flavonoids. Each value is the mean of three replicates. Any two means having a common alphabet are not significantly different at $p=0.05$ using LSD. Vertical bar represents the standard error of the 3 means. WT $=$ wild-type plant, TB1-TB4 $=$ rol $B$ transgenics, $\mathrm{TC} 1-\mathrm{TC} 3=\mathrm{ro} / \mathrm{C}$ gene transgenics

reached $70 \mu \mathrm{g} / \mathrm{g}$ DW, showing a 2.4-fold increase, and in rol $C$ transformants $60 \mu \mathrm{g} / \mathrm{g} \mathrm{DW}$, showing a 2-fold increase. These concentrations, and those of the following flavonoids, are the average values. The concentration of quercetin was $10 \mu \mathrm{g} / \mathrm{g} \mathrm{DW}$ in the wild-type plant, increasing up to 6 -fold to $59 \mu \mathrm{g} / \mathrm{g}$ DW in the rol B transgenics and 4-fold to $40 \mu \mathrm{g} / \mathrm{g} \mathrm{DW}$ in $\mathrm{rol} C$ transgenics. The wild-type concentration of isoquercetin was $400 \mu \mathrm{g} /$ g DW, increasing 1.9-fold to $770 \mu \mathrm{g} / \mathrm{g}$ DW in $\mathrm{rol} \mathrm{B}$ transformants and 1.6-fold to $660 \mu \mathrm{g} / \mathrm{g}$ DW in rol $C$ gene transformants. The concentration of rutin in the wild-type plant was $300 \mu \mathrm{g} / \mathrm{g} \mathrm{DW}$, increasing up to 2.4fold to $720 \mu \mathrm{g} / \mathrm{g}$ DW in rol B transformants and 1.6-fold to $570 \mu \mathrm{g} / \mathrm{g}$ DW in $\mathrm{rol} C$ transformants.

Catechin and apigenin were detected in the transformed but not in the wild-type plants. In $\operatorname{rol} B$ and $r o l$ $C$ transformants the concentration of catechin was $75 \mu \mathrm{g} / \mathrm{g}$ DW and $60 \mu \mathrm{g} / \mathrm{g} \mathrm{DW}$, respectively, and that of apigenin $42 \mu \mathrm{g} / \mathrm{g}$ DW and $30 \mu \mathrm{g} / \mathrm{g}$ DW, respectively. Thus, the production levels of the studied compounds in wild-type $A$. carvifolia showed a highly significant statistical difference $(P=0.000)$ in comparison with the $\operatorname{rol} B$ and rol $C$ transgenics (Table 1).

Polyphenols or flavonoids have been previously detected in different Artemisia species, as mentioned in the introduction, but in far less quantity. Rol $A B C$ genes are known to be reliable enhancers of secondary metabolite production [23-25]. The effects of individual rol genes from the TL-DNA of $A$. rhizogenes, A4 strain, on ginsenoside production in $P$. ginseng cell cultures has been reported, with rol $C$ cultures accumulating 1.8-3fold more ginsenoside than the control plant, while $\operatorname{rol} B$ lines were not more productive [26]. However, another study found that anthraquinone production increased in Rubia cardifolia when transformed with the rol B gene. Several reports describe the mechanism of action of the rol $B$ gene [17, 27, 28]. Kiani et al. (2015) observed increased flavonoid and phenolic content in A. dubia after transformation with a rol $A B C$ gene construct [29].

\section{Expression of flavonoid biosynthetic pathway genes through real time qPCR}

Significant changes in the expression of flavonoid biosynthetic pathway genes $(P A L, C H S)$ were observed in rol gene transgenics compared to untransformed plants (Fig. 3). The qPCR analysis clearly showed that both target genes were significantly more highly expressed $(\mathrm{P}<0.0001)$ in the transformed plants, particularly $P A L$. Increased gene expression in rol $B$ transformants was 8-21-fold for $P A L$ versus 3-6-fold for CHS. Among all the rol B transgenic lines, TB4 with two integrated copies of the rol $B$ gene showed the highest expression of both $P A L$ and CHS. Similarly, in rol $C$ transformants expression was 10-19-fold higher for $P A L$ and 3-5.8fold higher for $C H S$, reaching a maximum in line $\mathrm{TC} 1$, harboring two copies of the rol $C$ gene.

It has previously been described that the $P A L$ enzyme catalyzes the flux of primary metabolites into the 
Table 1 Analysis of variance for factors effecting the production of flavonoids in transgenics of rol $B$ and rol $C$ genes

\begin{tabular}{|c|c|c|c|c|c|}
\hline Source of variation & Degree of freedom & Sum of squares & Mean square & F-Value & Prob. \\
\hline Transgenic lines (A) & 7 & 0.763 & 0.109 & 6.6646 & 0.0000 \\
\hline Flavonoids (B) & 5 & 9.591 & 1.918 & 117.2688 & 0.0000 \\
\hline Transgenic lines X Flavonoids (AXB) & 35 & 2.051 & 0.059 & 3.5824 & 0.0000 \\
\hline Error & 96 & 1.570 & 0.016 & & \\
\hline Total & 143 & 13.976 & & & \\
\hline
\end{tabular}

Coefficient of variation: $29.63 \%$

biosynthetic pathway of flavonoids through the phenylpropanoid pathway and hence performs a key role in flavonoid biosynthesis [6,30]. CHS, the first enzyme of the flavonoid pathway, is an acyltransferase catalyzing the condensation of 4-coumaroyl CoA to the first flavonoid, naringenin chalcone, which is reported to be a ratelimiting step in flavonoid biosynthesis in different plants $[6,31,32]$. In walnut, $C H S$ is expressed more in leaves and buds than in liber and bark and is absent from wood and medulla [33]. Various reports describe that expression of PAL and CHS is directly related to the accumulation of flavonoids in the plant tissue [34, 35]. In the current study, a positive correlation was found in the studied flavonoid accumulation and expression of the $P A L$ and $C H S$ genes, in agreement with previous reports $[35,36]$. Other studies have also demonstrated that the overexpression of structural flavonoid biosynthetic pathway genes, including $P A L$ and $C H S$, is related to an increased flavonoid accumulation pattern [36, 37].

\section{Evaluation of the antioxidant potential of wild-type $A$. carvifolia and rol gene transgenics}

To assess the antioxidant potential of the transformed and untransformed $A$. carvifolia plants, different antioxidant assays were performed. Total antioxidant capacity, measured as the equivalent of ascorbic acid $(\mathrm{mg} / \mathrm{g}$ of the DW), was $0.53 \%$ (Fig. 4a) in the wild-type plant, compared to $0.76 \%$ in $\mathrm{rol} \mathrm{B}$ and $0.7 \%$ in $\mathrm{rol} C$ gene transformants. Total reducing power was also enhanced in the transgenics, being up to $3.4 \%$ for $\mathrm{rol} B$ and $3 \%$ for rol $C$, compared with $2 \%$ in the wild-type plant (Fig. 4a). Likewise, transformed plants showed lower IC50 values for anti-lipid peroxidation (Fig. 4b) and DPPH free radical scavenging activity (Fig. 4c); they were also more active in protecting the DNA against free hydroxyl radical-induced damage (Fig. 5). Rol genes showed highly significant effect i.e. $p=0.0000$ on the antioxidant potential of the plant under study (Tables 2 and 3). All these findings suggest that the integration of the $\operatorname{rol} B$ and $\operatorname{rol} C$ genes enhanced the antioxidant potential of the respective transgenic lines.

Oxidative stress is considered the root cause of the pathogenesis of many diseases, and antioxidants can be an effective treatment $[38,39]$. The study of antioxidantcontaining plant extracts provides insight into the mechanisms of action responsible for plant defense against oxidative damage, as well as identifying the specific antioxidant constituents [40]. The current study demonstrates that methanolic extracts of A. carvifolia have significant antioxidant properties.

Polyphenols are major plant antioxidants due to their redox capacity [41]. They play an important role in neutralizing or quenching free radicals and decomposing peroxides [42]. DPPH is an organic radical widely used in analyzing the antioxidant potential of pure compounds and plant extracts [43]. The reaction between the antioxidant and DPPH mainly depends on the hydrogen-donating ability, and therefore the structural

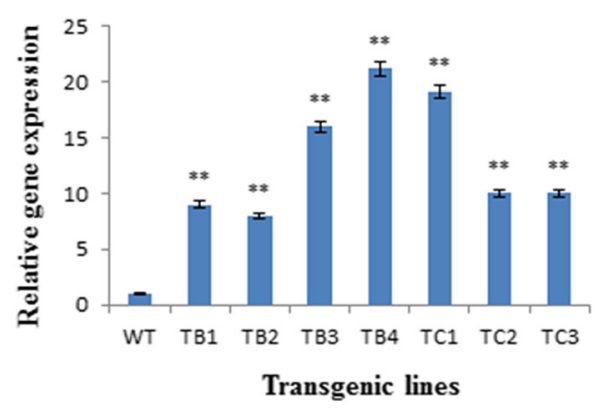

(a)

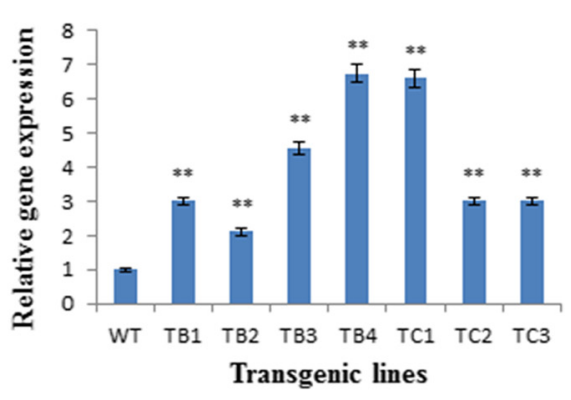

(b)

Fig. 3 Relative expression of flavonoid biosynthetic pathway genes: Relative expression of flavonoid biosynthetic pathway genes PAL (a) and CHS (b) in wild-type $A$. carvifolia and rol B and rol C transgenics. WT = wild-type plant, TB1-TB4 = rol B transgenics, TC1-TC3 $=$ rol C gene transgenics 


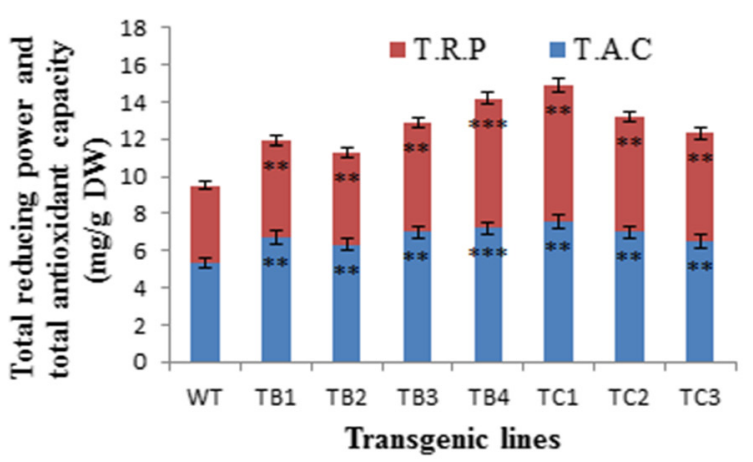

(a)

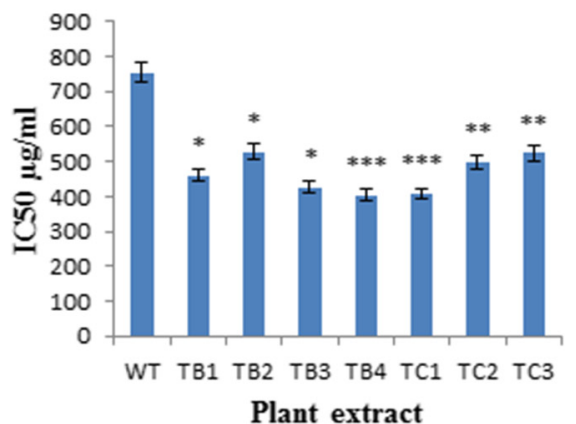

(b)

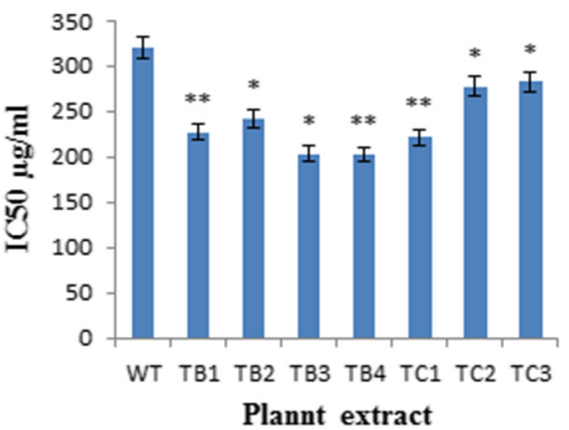

(c)

Fig. 4 Antioxidant capacities of wild-type A. carvifolia and rol $B$ and rol $C$ transgenics. Comparison of wild-type A. carvifolia with transgenics of $\mathrm{rol} B$ and $\mathrm{rol} C$ genes for total reducing power and total antioxidant capacity $(\mathbf{a}), I C_{50}$ for antilipid peroxidation assay $(\mathbf{b})$ and DPPH free radical scavenging assay (c). Error bars indicate the S.E. of triplicates. Statistical significance was measured by $t$-test $\left(*^{*}=P<0.01 ;{ }^{*}=P<0.05\right)$. WT $=$ wild-type plant, TB1-TB4 = rol B transgenics, TC1-TC3 = rol C gene transgenics

confirmation, of the former [44]. The reducing power of any compound or plant extract is in fact its potential to transfer electrons, which indicates its antioxidant capacity [45]. The ferric reducing power assay is used to evaluate the antioxidant potential of dietary polyphenols [46]. The reducing capacity shown by plant extracts indicates their antioxidant activity [47].

The antioxidant properties of methanolic extracts of Artemisia species have been correlated with their phenolic and flavonoid content [48]. Experiments have been performed to understand the relationship between secondary metabolism activation and reactive oxygen species production (ROS) in $R$. cardifolia transformed with the $\operatorname{rol} B$ [49] and rol $C$ genes [14, 50]. A significant reduction in intracellular ROS level was observed in the transformed cells of $R$. cardifolia, thus indicating that the rol $B$ and $r o l C$ genes are potential suppressors of ROS. This decrease in ROS was also accompanied by the enhanced expression of genes encoding ROS detoxifying enzymes $[49,50]$.

\section{Conclusion}

It can be concluded from the results that rol genes are effective in increasing flavonoid levels of $A$. carvifolia
Buch, as confirmed by the HPLC-DAD analysis and enhanced antioxidant potential of rol gene transformants. The transgenic plants also had higher transcript levels of genes involved in flavonoid biosynthesis than the wildtype plants, which was in accordance with their higher flavonoid content. The rol $B$ gene was more effective than the rol $C$ gene in promoting secondary metabolism in A. carvifolia Buch.

\section{Methods}

Seeds of Artemisia carvifolia were collected from Astore, in the Northern regions of Pakistan $\left(35.3667^{\circ} \mathrm{N}\right.$, $74.8500^{\circ} \mathrm{E} ; 8500 \mathrm{ft}$ elevation) and grown on half strength MS medium. Identification of Artemisia carvifolia Buch was done at the Herbarium of Quaid-i-Azam University, Islamabad, Pakistan, where the specimen voucher number was submitted. After that, identification was confirmed through DNA barcoding [21]. Wild-type plants of $A$. carvifolia, as well as four rol $B$ transgenic lines and three rol $C$ transgenic lines produced previously [21], were analyzed for flavonoid content variation and also by real time qPCR to determine the expression of flavonoid biosynthetic genes. Additionally, the antioxidant potential of all the plants under study was determined. 


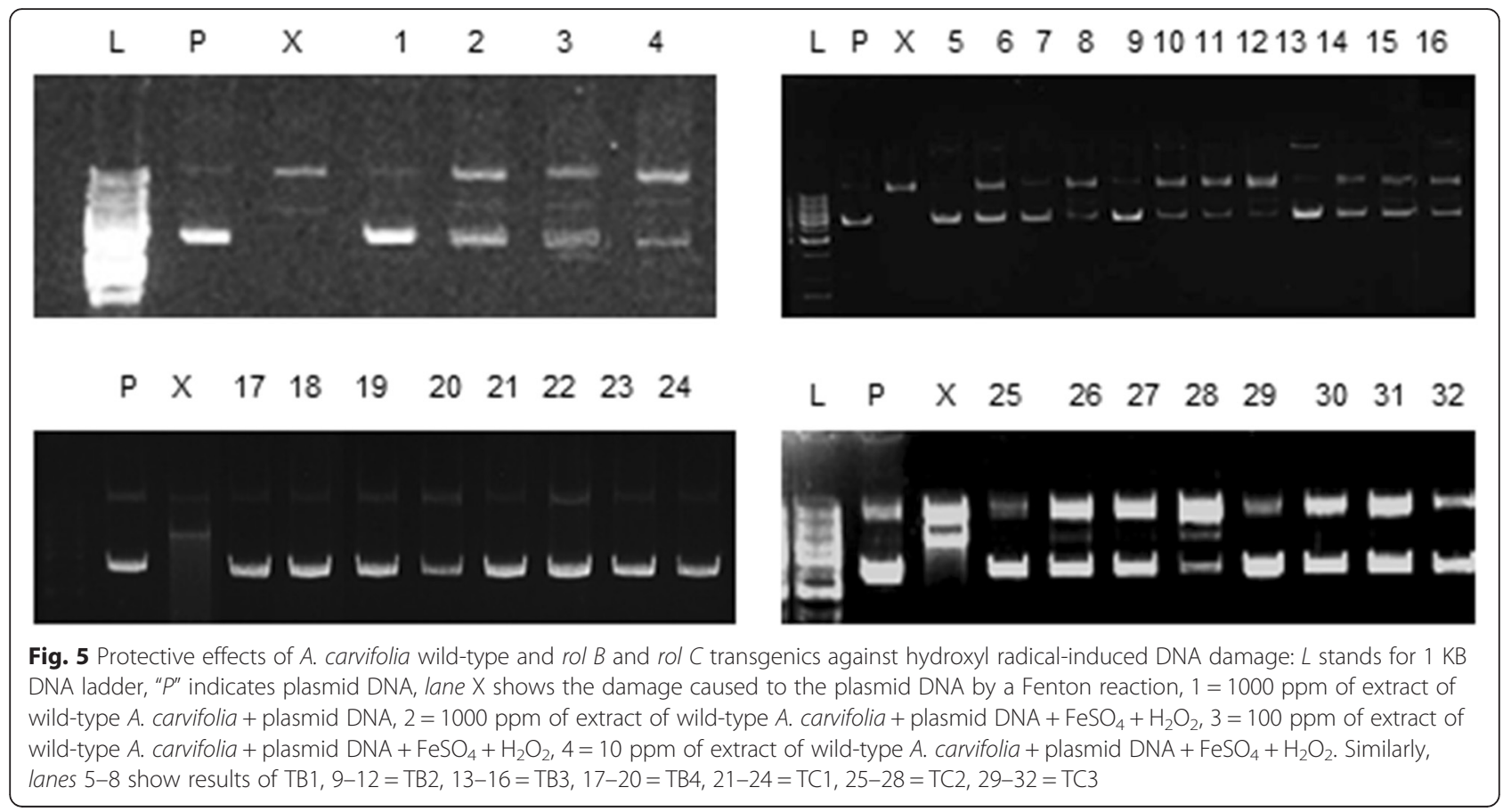

\section{Analysis of flavonoids through an HPLC-DAD system}

Extraction of flavonoids from shoots of wild-type plants and $r o l$ gene transgenics (4-months old) was carried out according to the reported procedure [51]. Qualitative and quantitative analysis of flavonoids was carried out using a Waters Acuity ${ }^{\mathrm{TM}}$ HPLC-DAD system (Waters, Spain) attached to a symmetry C-18 analytical column with dimensions of $5 \mu \mathrm{m}, 3.9 \times 150 \mathrm{~mm}$ (Waters, Spain). The wavelength was adjusted to $235-450 \mathrm{~nm}$, and pressure applied was 200 psi. Separation was achieved using a mobile phase of acetonitrile with $0.5 \%$ formic acid (A) and water with $0.5 \%$ formic acid (B) running at a flow rate of $1 \mathrm{ml} / \mathrm{min}$, with the following gradient ( $\mathrm{t}(\mathrm{min}$ ), $\% \mathrm{~B}):(0,95)(15,65)(18,10)(22,95)$. The injection volume was $10 \mu \mathrm{l}$ and retention time was $27 \mathrm{~min}$. Peaks in extracts were identified by comparison with retention indices of reference standards. The analytes were detected at wavelengths specific for each metabolite with a particular retention time (Table 4).
Real time qPCR of flavonoid biosynthetic pathway genes Expression of flavonoid biosynthetic pathway genes was studied by real time qPCR according to a previously reported method [21]. The amplification reaction was performed by gene-specific primers, i.e. PAL forward: $5^{\prime}$ ACACTCGGTTAGCTATTGCTGCAA $-3^{\prime}$ and reverse: 5' - CCATGGCGATTTCTGCACCT -3', CHS forward: 5'-AGGCTAACAGAGGAGGGTA-3' and reverse: $5^{\prime}$ CCAATTTACCGGCTTTCT -3 ', actin forward 5' ATCAGCAATACCAGGGAACATAGT-3' and reverse 5'-AGGTGCCCTGAGGTCTTGTTCC-3' .

\section{Measurement of antioxidant potential}

The antioxidant potential of all the plants under study was determined by performing in vitro antioxidant assays. Thus, a methanolic extract of $1 \mathrm{~g}$ air-dried shoots was prepared after fine-grinding. Briefly, $1 \mathrm{~g}$ dried powdered plant material was extracted with $3 \mathrm{ml}$ of methanol and subjected to sonication for half an hour. The

Table 2 ANOVA for antilipid peroxidation assay

\begin{tabular}{llrrr}
\hline Source of variation & $\begin{array}{l}\text { Degree of } \\
\text { freedom }\end{array}$ & Sum of squares & Mean square & F-Value \\
\hline Concentrations (A) & 2 & 14254.201 & 7127.100 & 8545.4007 \\
Genotype (B) & 7 & 211.206 & 30.172 & 36.1766 \\
Concentration X & 14 & 246.106 & 17.579 & 21.0772 \\
Genotype (AXB) & 48 & & & 0.0000 \\
Error & 71 & 40.033 & & 0.0000 \\
Total & 414751.546 & & \\
\hline
\end{tabular}

Coefficient of variation: $1.91 \%$ 
Table 3 ANOVA for DPPH free radical scavenging assay

\begin{tabular}{llcrr}
\hline Source of variation & $\begin{array}{l}\text { Degree of } \\
\text { freedom }\end{array}$ & Sum of squares & Mean square & F-Value \\
\hline Concentrations (A) & 2 & 15107.802 & 7553.90 & 101470.30 \\
Genotype (B) & 7 & 1849.574 & 264.22 & 3549.28 \\
Concentration X & 14 & 2339.980 & 167.14 & 2245.18 \\
Genotype (AXB) & & & & 0.0000 \\
Error & 48 & 3.573 & & 0.00000 \\
Total & 71 & 19300.930 & & \\
\hline
\end{tabular}

Coefficient of variation: $2.15 \%$

extract was then centrifuged at $4000 \mathrm{~g}$ for $10 \mathrm{~min}$, the supernatant was dried, and the residue was dissolved in DMSO to reach a final concentration of $100 \mathrm{mg} / \mathrm{ml}$.

\section{Measurement of total antioxidant capacity}

Total antioxidant capacity was determined according to the reported methodology [52] using a 96-well plate. Initially, $4 \mu \mathrm{l}$ of the plant extract $(100 \mathrm{mg} / \mathrm{ml})$ was added to the wells and then $196 \mu \mathrm{l}$ of the total antioxidant capacity reagent was added. After incubating the mixture for $90 \mathrm{~min}$ at $90{ }^{\circ} \mathrm{C}$ in a water bath, its color changed to dark blue. The mixture was then cooled and sample absorbance was taken at $630 \mathrm{~nm}$ on a microplate reader (Biotek, Elx 800). Ascorbic acid was used as a positive control and DMSO was used as a negative control. The total antioxidant capacity of the sample was calculated using the following formula:

\section{Ascorbic Acid Equivalence $=100 / 2.651 \times$ Absorbance of sample $\mu \mathrm{g} / \mathrm{ml}$}

\section{Measurement of total reducing power}

The total reducing power of $A$. carvifolia transformed and untransformed plant extracts was determined [53] using a 96-well plate. Twenty microlitres of plant extract $(100 \mathrm{mg} / \mathrm{ml})$ was added to the Eppendorf tubes together with $490 \mu \mathrm{l}$ of $0.2 \mathrm{M}$ phosphate buffer and $490 \mu \mathrm{L}$ of $1 \%$ potassium ferricyanide, which was incubated at $50^{\circ}$

$\mathrm{C}$ for $20 \mathrm{~min}$. Five-hundred microlitres of trichloroacetic

Table 4 Retention time of studied flavonoids with wavelength

\begin{tabular}{lllc}
\hline S. No & Standard & Wavelength $(\mathrm{nm})$ & $\begin{array}{c}\text { Retention } \\
\text { time }(\mathrm{min})\end{array}$ \\
\hline 1 & Apigenin & 325 & 20.2 \\
2 & Caffeic acid & 325 & 8.7 \\
3 & Catechin & 279 & 10.7 \\
4 & Isoquercetin & 355 & 11.1 \\
5 & Quercetin & 370 & 15.1 \\
6 & Rutin & 355 & 10.8 \\
\hline
\end{tabular}

acid was added to the Eppendorf tubes and the mixture was centrifuged at $3000 \mathrm{rpm}$ for $10 \mathrm{~min}$. Five-hundred microlitres of the supernatant was isolated in a new Eppendorf tube and $100 \mu \mathrm{l}$ of ferric chloride was added. The color of the ferric chloride changed to blue on reduction. Two-hundred microlitres of this sample was poured into the wells. Absorbance of the samples was taken at $630 \mathrm{~nm}$ on a microplate reader. Ascorbic acid and DMSO were used as positive and negative controls, respectively. The reducing power of the sample was calculated using the following formula:

$$
\begin{aligned}
& \text { Ascorbic Acid Equivalence } \\
& =100 / 2.7025 \times \text { Absorbance of sample } \mu \mathrm{g} / \mathrm{ml}
\end{aligned}
$$

\section{Anti-lipid peroxidation assay}

The method for the anti-lipid peroxidation assay was adapted from Kanagalakshmi et al. [54]. Vitamin E and plain DMSO were used as positive and negative controls, respectively. Plant extracts were tested at the concentration of 1000, 100 and $10 \mathrm{ppm}$. Twenty microlitres of plant extract at each concentration was added to the liposomes in which lipid peroxidation had been induced. Incubation was carried out at $37{ }^{\circ} \mathrm{C}$ for $1 \mathrm{~h}$. One milliliter of stopping solution was added to stop the reaction, which was boiled for $15 \mathrm{~min}$ and then cooled. TwoHundred microlitres of the resulting solution was placed in the wells of a 96-well plate. Absorbance was measured at $532 \mathrm{~nm}$. The \% inhibition and $\mathrm{IC}_{50}$ value was calculated with TableCurve software.

\section{DPPH free radical scavenging assay}

Free radical scavenging activity of all the plant extracts was measured according to the reported method [55] with minor modification as given below. The assay was run on four different concentrations of plant extract (1000, 500, 250 and 125 ppm) in a 96-well microplate. Briefly, $20 \mu \mathrm{l}$ of each plant extract, or DMSO in the negative control and ascorbic acid in the positive control, was mixed with $180 \mu \mathrm{l}$ of $0.1 \mathrm{mM}$ freshly prepared $\mathrm{DPPH}$ solution. All the extracts at each concentration 
were run in triplicate. Incubation at $37{ }^{\circ} \mathrm{C}$ for half an hour was carried out for all the reaction mixtures. After that, absorbance was taken at $517 \mathrm{~nm}$.

\section{Oxidative DNA damage analysis}

A previously reported method [56] was adopted to find the antioxidant and prooxidant activity of the extracts of the plants under study. Fifty millimetre phosphate buffer was used to dissolve the pBR322 plasmid DNA to reach a concentration of $0.5 \mu \mathrm{g} / 3 \mu \mathrm{l}$. Plant extracts were analyzed at three different concentrations, i.e. 1000, 100, and $10 \mathrm{ppm}$. Plasmid pBR322 with the damaging agent, i.e. FeSO4 and $\mathrm{H}_{2} \mathrm{O}_{2}$, served as a positive control for DNA damage, whereas pBR322 DNA alone in phosphate buffer was used as the negative control. Incubation was done at $37{ }^{\circ} \mathrm{C}$ for $60 \mathrm{~min}$. After that, samples were run on $1 \%$ agarose gel and photographed under UV.

\section{Statistical analysis}

All the experiments, including flavonoid extraction, HPLC analysis, real time qPCR and antioxidant assays, were performed in triplicate with the S.E. calculated. The data obtained by HPLC analysis was analyzed statistically by applying ANOVA and Duncan's multiple range tests. Antioxidant assays were also analyzed statistically by ANOVA. The statistical significance of the results of the gene expression analysis and total antioxidant capacity and reducing power was determined by a $t$-test $(p<0.01=* *, p<0.05=*)$.

\section{Abbreviations}

CHS: chalcone synthase; DMSO: dimethyl sulfoxide; DPPH: 2,2-diphenyl-1picrylhydrazyl; DW: dry weight; MS: murashige and skoog; PAL: phenylalanine ammonia-lyase; ROS: reactive oxygen species; TBE: tris buffer EDTA.

\section{Acknowledgements}

We are thankful to the Higher Education Commission of Pakistan for providing a scholarship to author Erum Dilshad during her PhD. We also appreciate the intellectual support provided by Dr. Mercedes Bonfill and Dr. Mohammad Tahir Waheed.

\section{Funding}

No funding was obtained for the research project.

\section{Availability of data and materials}

The datasets supporting the conclusions of this article are included within the article.

\section{Authors' contributions}

$\mathrm{ED}$ and $\mathrm{HI}$ carried out the practical work regarding all experiments, i.e. real time qPCR, HPLC and antioxidant assays. IUH designed and helped in conducting the HPLC analysis. RMC \& JP supervised all the work performed in the Department of Pharmacy, University of Barcelona, Spain. They also reviewed the manuscript intellectually and critically to give it final form for publication. KR provided technical as well as intellectual support in doing real time quantitative PCR analysis. She also contributed to the experimental design. BM supervised all the work performed in the Plant Molecular Biology Laboratory of QAU, Islamabad, Pakistan. She also helped in writing the manuscript and its proofreading. All authors have read and approved the final version of the paper.

\section{Competing interests}

The authors declare that they have no competing interests.

Consent for publication

Not applicable.

Ethics approval and consent to participate

The project was approved by the Institutional Biosafety Committee (IBC) Quaid-i-Azam University Islamabad, Pakistan.

\section{Author details}

${ }^{1}$ Department of Biochemistry, Faculty of Biological Sciences, Quaid-i-Azam University, Islamabad, Pakistan. ²Department of Pharmacy, Quaid-i-Azam University, Islamabad, Pakistan. ${ }^{3}$ Laboratorio de Fisiologia Vegetal, Facultad de Farmacia, Universidad de Barcelona, Barcelona, Spain.

Received: 23 March 2016 Accepted: 17 May 2016

Published online: 02 June 2016

\section{References}

1. Bremer K, Humphries C. Generic monograph of the AsteraceaeAnthemideae. Bull Nat Hist Mus London (Bot). 1993;23(2):71-177.

2. Chaurasia OP, Ahmed Z, Ballabh B. Ethnobotany and plants of transHimalaya. New Delhi: Satish Serial Pub. House; 2007.

3. Pillay P, Maharaj VJ, Smith PJ. Investigating South African plants as a source of new antimalarial drugs. J Ethnopharmacol. 2008;119(3):438-54.

4. Lai H, Singh NP. Oral artemisinin prevents and delays the development of 7 , 12-dimethylbenz [a] anthracene (DMBA)-induced breast cancer in the rat. Cancer Lett. 2006;231(1):43-8.

5. Patra B, Schluttenhofer C, Wu Y, Pattanaik S, Yuan L. Transcriptional regulation of secondary metabolite biosynthesis in plants. Biochim Biophys Acta, Gene Regul Mech. 2013;1829(11):1236-47.

6. Lucheta AR, Silva-Pinhati ACO, Basílio-Palmieri AC, Berger IJ, Freitas-Astúa J, Cristofani M. An in silico analysis of the key genes involved in flavonoid biosynthesis in Citrus sinensis. Genet Mol Biol. 2007;30(3):819-31.

7. Ritter $H$, Schulz GE. Structural basis for the entrance into the phenylpropanoid metabolism catalyzed by phenylalanine ammonia-lyase. Plant Cell. 2004;16(12):3426-36.

8. Ferreira JF, Luthria DL, Sasaki T, Heyerick A. Flavonoids from Artemisia annua L. as antioxidants and their potential synergism with artemisinin against malaria and cancer. Molecules. 2010;15(5):3135-70.

9. Singh R, Verma PK, Singh G. Total phenolic, flavonoids and tannin contents in different extracts of Artemisia absinthium. J Intercult Ethnopharmacol. 2012;1(2):101-4

10. Hajdú Z, Martins A, Orbán-Gyapai O, Forgo P, Jedlinszki N, Máthé I, et al. Xanthine oxidase-inhibitory activity and antioxidant properties of the methanol extract and flavonoids of Artemisia asiatica. Rec Nat Prod. 2014;8(3):299-302

11. Qnais E, Raad D, Bseiso Y. Analgesic and anti-inflammatory effects of an extract and flavonoids from Artemisia Herba-Alba and their mechanisms of action. Neurophysiology. 2014;46(3):238-46.

12. Baraldi R, Isacchi B, Predieri S, Marconi G, Vincieri FF, Bilia AR. Distribution of artemisinin and bioactive flavonoids from Artemisia annua L. during plant growth. Biochem Syst Ecol. 2008;36(5):340-8.

13. Bourgaud F, Gravot A, Milesi S, Gontier E. Production of plant secondary metabolites: a historical perspective. Plant Sci. 2001;161(5):839-51.

14. Bulgakov VP. Functions of rol genes in plant secondary metabolism. Biotechnol Adv. 2008:26(4):318-24.

15. Filippini F, Schiavo FL, Terzi M, Costantino P, Trovato M. The plant oncogene rolB alters binding of auxin to plant cell membranes. Plant Cell Physiol. 1994;35(5):767-71.

16. Kiselev K, Dubrovina A, Veselova M, Bulgakov V, Fedoreyev S, Zhuravlev YN. The rolB gene-induced overproduction of resveratrol in Vitis amurensis transformed cells. J Biotechnol. 2007;128(3):681-92.

17. Shkryl YN, Veremeichik GN, Bulgakov VP, Tchernoded GK, Mischenko NP, Fedoreyev SA, et al. Individual and combined effects of the rolA, B, and C genes on anthraquinone production in Rubia cordifolia transformed calli. Biotechnol Bioeng. 2008;100(1):118-25.

18. Bulgakov V, Tchernoded GK, Mischenko N, Shkryl YN, Glazunov V, Fedoreyev S, et al. Effects of Ca2+ channel blockers and protein kinase/phosphatase 
inhibitors on growth and anthraquinone production in Rubia cordifolia callus cultures transformed by the rolB and rolC genes. Planta. 2003;217(3):349-55.

19. Bulgakov VP, Veselova M, Tchernoded G, Kiselev K, Fedoreyev S, Zhuravlev YN. Inhibitory effect of the Agrobacterium rhizogenes rolC gene on rabdosiin and rosmarinic acid production in Eritrichium sericeum and Lithospermum erythrorhizon transformed cell cultures. Planta. 2005;221(4):471-8.

20. Palazón J, Cusidó R, Roig C, Pinol M. Expression of the rolC gene and nicotine production in transgenic roots and their regenerated plants. Plant Cell Rep. 1998;17(5):384-90

21. Dilshad E, Cusido RM, Estrada KR, Bonfill M, Mirza B. Genetic transformation of Artemisia carvifolia Buch with rol genes enhances artemisinin accumulation. PLoS One. 2015;10(10), e0140266.

22. Dilshad E, Cusido RM, Palazon J, Estrada KR, Bonfill M, Mirza B. Enhanced artemisinin yield by expression of rol genes in Artemisia annua. Malar J. 2015;14(1):424

23. Bensaddek L, Villarreal ML, Fliniaux M-A. Induction and growth of hairy roots for the production of medicinal compounds. Electronic Journal of Integrative Biosciences. 2008;3(1, Special Issue on Hairy Roots (A. Lorence and F. Medina-Bolivar, co-editors)):2-9.

24. Wang J, Zheng $L$, Tan $R$. The preparation of an elicitor from a fungal endophyte to enhance artemisinin production in hairy root cultures of Artemisia annua L. Chin J Biotechnol. 2006;22(5):829.

25. Putalun W, Luealon W, De-Eknamkul W, Tanaka H, Shoyama Y. Improvement of artemisinin production by chitosan in hairy root cultures of Artemisia annua L. Biotechnol Lett. 2007;29(7):1143-6.

26. Bulgakov VP, Khodakovskaya MV, Labetskaya NV, Chernoded GK, Zhuravlev YN. The impact of plant rolC oncogene on ginsenoside production by ginseng hairy root cultures. Phytochemistry. 1998;49(7):1929-34.

27. Estruch J, Schell J, Spena A. The protein encoded by the rolB plant oncogene hydrolyses indole glucosides. EMBO J. 1991;10(11):3125.

28. Maurel C, Leblanc N, Barbier-Brygoo H, Perrot-Rechenmann C, BouvierDurand M, Guern J. Alterations of auxin perception in rolB-transformed tobacco protoplasts (time course of rolB mRNA expression and increase in auxin sensitivity reveal multiple control by auxin). Plant Physiol. 1994; 105(4):1209-15.

29. Kiani BH, Ullah N, Haq I-U, Mirza B. Transgenic Artemisia dubia WALL showed altered phytochemistry and pharmacology. Arab J Chem. 2015. doi: 10.1016/j.arabjc.2015.04.020

30. Chang J, Luo J, He G. Regulation of polyphenols accumulation by combined overexpression/silencing key enzymes of phyenylpropanoid pathway. Acta Biochim Biophys Sin. 2009;41(2):123-30.

31. Bovy A, Schijlen E, Hall RD. Metabolic engineering of flavonoids in tomato (Solanum lycopersicum): the potential for metabolomics. Metabolomics. 2007;3(3):399-412.

32. Pitakdantham W, Sutabutra T, Chiemsombat P, Pitaksutheepong C. Isolation and characterization of chalcone synthase gene isolated from Dendrobium Sonia Earsakul. Pak J Biol Sci. 2010;13(20):1000-5.

33. Claudot A-C, Ernst D, Sandermann H, Drouet A. Cloning and characterization of two members of the chalcone synthase gene family from walnut. Plant Physiol Biochem. 1999;37(10):721-30.

34. Gupta N, Sharma SK, Rana JC, Chauhan RS. Expression of flavonoid biosynthesis genes vis-à-vis rutin content variation in different growth stages of Fagopyrum species. J Plant Physiol. 2011;168(17):2117-23.

35. Nakatsuka A, Mizuta D, Kii Y, Miyajima I, Kobayashi N. Isolation and expression analysis of flavonoid biosynthesis genes in evergreen azalea. Sci Hortic. 2008;118(4):314-20.

36. Jaakola L, Määttä K, Pirttilä AM, Törrönen R, Kärenlampi S, Hohtola A Expression of genes involved in anthocyanin biosynthesis in relation to anthocyanin, proanthocyanidin, and flavonol levels during bilberry fruit development. Plant Physiol. 2002;130(2):729-39.

37. Jackson D, Roberts K, Martin C. Temporal and spatial control of expression of anthocyanin biosynthetic genes in developing flowers of Antirrhinurn majus. Plant J. 1992;2:425-34.

38. Reaven PD, Herold DA, Barnett J, Edelman S. Effects of vitamin E on susceptibility of low-density lipoprotein and low-density lipoprotein subfractions to oxidation and on protein glycation in NIDDM. Diabetes Care. 1995;18(6):807-16.

39. Cunningham JJ. Micronutrients as nutriceutical interventions in diabetes mellitus. J Am Coll Nutr. 1998;17(1):7-10.
40. Liao H, Banbury LK, Leach DN. Antioxidant activity of 45 Chinese herbs and the relationship with their TCM characteristics. Evid Based Complement Alternat Med. 2008;5(4):429-34.

41. Tepe B, Sokmen M, Akpulat HA, Sokmen A. Screening of the antioxidant potentials of six Salvia species from Turkey. Food Chem. 2006;95(2):200-4.

42. Brand-Williams W, Cuvelier M, Berset C. Use of a free radical method to evaluate antioxidant activity. LWT- Food Sci Technol. 1995;28(1):25-30.

43. Katalinic $V$, Milos M, Kulisic T, Jukic M. Screening of 70 medicinal plant extracts for antioxidant capacity and total phenols. Food Chem. 2006; 94(4):550-7.

44. Baumann J, Wurm G, Von Bruchhausen F. [Prostaglandin synthetase inhibition by flavonoids and phenolic compounds in relation to their O2scavenging properties (author's transl)]. Arch Pharm. 1980;313(4):330-7.

45. Meir S, Kanner J, Akiri B, Philosoph-Hadas S. Determination and involvement of aqueous reducing compounds in oxidative defense systems of various senescing leaves. J Agric Food Chem. 1995;43(7):1813-9.

46. Luximon-Ramma A, Bahorun T, Soobrattee MA, Aruoma OI. Antioxidant activities of phenolic, proanthocyanidin, and flavonoid components in extracts of Cassia fistula. J Agric Food Chem. 2002;50(18):5042-7.

47. Hazra B, Biswas S, Mandal N. Antioxidant and free radical scavenging activity of Spondias pinnata. BMC Complement Altern Med. 2008;8(1):63.

48. Wright CW. Artemisia. Boca Raton: CRC Press; 2003

49. Bulgakov VP, Gorpenchenko TY, Veremeichik GN, Shkryl YN, Tchernoded GK, Bulgakov DV, et al. The rolB gene suppresses reactive oxygen species in transformed plant cells through the sustained activation of antioxidant defense. Plant Physiol. 2012;158(3):1371-81.

50. Shkryl Y, Veremeichik G, Bulgakov V, Gorpenchenko T, Aminin D, Zhuravlev $Y$. Decreased ROS level and activation of antioxidant gene expression in Agrobacterium rhizogenes pRiA4-transformed calli of Rubia cordifolia. Planta. 2010;232(5):1023-32.

51. Zu Y, Li C, Fu Y, Zhao C. Simultaneous determination of catechin, rutin, quercetin kaempferol and isorhamnetin in the extract of sea buckthorn (Hippophae rhamnoides L.) leaves by RP-HPLC with DAD. J Pharm Biomed Anal. 2006;41(3):714-9.

52. Prieto $P$, Pineda M, Aguilar M. Spectrophotometric quantitation of antioxidant capacity through the formation of a phosphomolybdenum complex: specific application to the determination of vitamin E. Anal Biochem. 1999;269(2):337-41.

53. Oyaizu M. Studies on products of browning reaction-antioxidative activities of products of browning reaction prepared from glucosamine. Jpn J Nutr. 1986.

54. Kanagalakshmi K, Premanathan M, Priyanka R, Hemalatha B, Vanangamudi A. Synthesis, anticancer and antioxidant activities of 7-methoxyisoflavanone and 2, 3-diarylchromanones. Eur J Med Chem. 2010;45(6):2447-52.

55. Nawaz H, Akhter Z, Yameen S, Siddiqi HM, Mirza B, Rifat A. Synthesis and biological evaluations of some Schiff-base esters of ferrocenyl aniline and simple aniline. J Organomet Chem. 2009;694(14):2198-203.

56. Tian B, Hua Y. Concentration-dependence of prooxidant and antioxidant effects of aloin and aloe-emodin on DNA. Food Chem. 2005;91(3):413-8.

57. Itoh Y, Higeta D, Suzuki A, Yoshida H, Ozeki Y. Excision of transposable elements from the chalcone isomerase and dihydroflavonol 4-reductase genes may contribute to the variegation of the yellow-flowered carnation (Dianthus caryophyllus). Plant and Cell Physiology 2002, 43(5):578-585.

\section{Submit your next manuscript to BioMed Central and we will help you at every step:}

- We accept pre-submission inquiries

- Our selector tool helps you to find the most relevant journal

- We provide round the clock customer support

- Convenient online submission

- Thorough peer review

- Inclusion in PubMed and all major indexing services

- Maximum visibility for your research

Submit your manuscript at www.biomedcentral.com/submit
C Biomed Central 